\title{
Experimental evaluation of preferences of an invasive Ponto-Caspian gammarid Pontogammarus robustoides (Amphipoda, Gammaroidea) for mineral and plant substrata
}

\author{
Łukasz Jermacz • Anna Dzierżyńska • \\ Małgorzata Poznańska · Jarosław Kobak
}

Received: 29 April 2014/Revised: 3 June 2014/Accepted: 21 June 2014/Published online: 17 July 2014

(C) The Author(s) 2014. This article is published with open access at Springerlink.com

\begin{abstract}
Pontogammarus robustoides has spread across Europe since the second half of the twentieth century. It is often regarded as a psammophilous and/ or phytophilous species. We studied preferences of $P$. robustoides for 5 mineral substrata of different grain sizes, 5 plant species and 3 artificial plants differing in leaf shape. We tested 10 gammarid individuals in 24-h pairwise choice tests in darkened tanks. Adults selected stones of $27 \pm 4.8$-mm grain diameter, rather than smaller or larger objects, whereas juveniles preferred particles of $15 \pm 3.2$-mm grain diameter. Structurally complex plants (natural and artificial) were most preferred for both age groups. Juveniles, unlike adults, preferred natural plants over artificial ones and mineral substrata. Adults preferred mineral materials over macrophytes and did not differentiate between natural and artificial plants. Juveniles did not avoid areas occupied by adults, but in their presence exhibited significantly stronger preferences for substrata providing them with suitable shelters. Habitats selected by gammarids in our study somewhat differed from those commonly used in the field, indicating their
\end{abstract}

Guest editors: Sidinei M. Thomaz, Katya E. Kovalenko, John E. Havel \& Lee B. Kats / Aquatic Invasive Species

Ł. Jermacz $(\bowtie) \cdot$ A. Dzierżyńska · M. Poznańska ·

J. Kobak

Department of Invertebrate Zoology, Nicolaus Copernicus University, Lwowska 1, 87-100 Toruń, Poland

e-mail: lukasjermacz@gmail.com high plasticity. Different preferences of adults and juveniles may help them avoid competition and/or cannibalism in the field.

Keywords Freshwater amphipods - Macrophytes · Stone substratum $\cdot$ Habitat selection $\cdot$ Habitat complexity · Grain size

\section{Introduction}

Habitat selection is a universal process, in which individuals must choose among habitats that differ in biotic and abiotic characteristics (Johnson, 1980; Huey, 1991). A classic trade-off in behavioural ecology is maximizing the acquisition of food while minimizing the risk of predation (Sih, 1980). To optimize their fitness, organisms should select those habitats that promote growth and survival and increase the probability of reproductive success (Pulliam \& Danielson, 1991; Murphy, 2003; Lehtinen \& Carfagno, 2011). Many variables can influence habitat selection and their relative importance can vary in space and time (Jansson et al., 1985; Clark \& Green, 1990; Lehtinen \& Carfagno, 2011). One of the most important factors determining the quality of a habitat is its complexity, which affects the structure of biological communities (Murdoch \& Oaten, 1975; Holt, 1984; Kovalenko et al., 2012) and relationships between organisms belonging to different trophic 
levels (Briand \& Cohen, 1987; Whitehead \& Walde, 1992) by changing their susceptibility to predators, competitive interactions and feeding (Engström-Öst et al., 2006). In particular, habitat fragmentation can produce edge effects promoting competition or predation (MacNeil \& Platvoet, 2013).

In the aquatic environment, one of the most important habitat components is substratum type, shaping living conditions for benthic organisms. Thus, the ability to choose a habitat with suitable substratum, allowing for further survival and reproductive success, is crucial for bottom-dwelling animals. Aquatic habitats are structured by different types of natural substrates, such as stones, leaves, branches, macrophytes and artificial substrata, such as solid waste materials, all of which exhibit positive effects on invertebrate diversity (Cooper et al., 1997; Scealy et al., 2007; Czarnecka et al., 2009). Macrophytes increase the availability of food and shelters, elevating the diversity of aquatic assemblages (Raizer \& Amaral, 2001; Taniguchi et al., 2003; Thomaz et al., 2008). Temperate shores throughout the world are dominated by macrophytes (Foster et al., 2003; Schiel, 2004). Not only diversity, but also invertebrate density and body size vary with the degree of habitat complexity provided by macrophytes (McAbendroth et al., 2005; Mormul et al., 2011). A similar habitat-shaping role is played by hard substratum, providing shelters and increasing the area for recruitment, especially when substratum architecture is complex (Taniguchi \& Tokeshi, 2004; Czarnecka et al., 2009).

Substratum quality may considerably affect the success of biological invaders in their novel areas. The ability to select an appropriate habitat is particularly important for these organisms, as outside their native range they have to face different abiotic (e.g. substratum type) and/or biotic (e.g. new predators, competitors and habitatforming macrophytes) environmental factors. Thus, the knowledge of habitat preferences of invasive species and their plasticity may help understand their invasion success and predict further spread. During the last decades, European waters have been heavily invaded by many macroinvertebrate species originating mostly from North America, East Asia and the Ponto-Caspian region (Van der Velde et al., 2000; Bij de Vaate et al., 2002; Devin \& Beisel, 2008). Gammarids, particularly of Ponto-Caspian origin, belong to the most successful aquatic invaders. To date, they account for $80-90 \%$ of the macroinvertebrate numbers as well as biomass in the
River Rhine (Van Riel et al., 2006). Biological traits contributing to their invasion success include high fecundity and omnivory (with a tendency to predation) (Van Riel et al., 2006; Platvoet et al., 2009b), while ecological traits comprise tolerance to wide spectra of chemical and physical factors, such as salinity, temperature, water flow and environmental pollution, as well as contagious distribution (Den Hartog et al., 1992).

One of the Ponto-Caspian invasive invertebrates in European waters is Pontogammarus robustoides (G.O. Sars) (Gruszka, 1999). It inhabits differentiated habitats (Bacela \& Konopacka, 2005; Żytkowicz et al., 2008; Czarnecka et al., 2009, 2010) in lentic parts of the River Vistula, Oder and Bug and some lakes in these rivers' valleys (Grabowski \& Bạcela, 2005; Grabowski et al., 2007b). So far, it has reached eastern Germany on its way west (Bij de Vaate et al., 2002; Grabowski et al., 2007a), though further expansion is likely. $P$. robustoides is often found in very shallow sandy areas, and its affinity for such locations is supported by its adaptations to survive temporary air exposure (Poznańska et al., 2013). At greater depths, particularly juveniles of this species often inhabit macrophytes (Czarnecka et al., 2009). On the other hand, it does not show any affinities for zebra mussels (Kobak \& Żytkowicz, 2007), as other Ponto-Caspian gammarids do. Adult $P$. robustoides seem to be generally less selective with regard to available habitats, being also commonly found on artificial solid wastes discarded into water (Czarnecka et al., 2009). Czarnecka et al. (2010) has shown in laboratory experiments that juvenile $P$. robustoides selects natural, structurally complex plants as their habitat, whereas habitat selectivity of adult individuals of this species is rather weak. However, to our knowledge, no attempt has been made to test preferences of $P$. robustoides for mineral substrata, despite the fact that it commonly occurs on bare sandy bottom (Gruszka, 1999; Żytkowicz et al., 2008; Poznańska et al., 2013) or to compare the relative strength of its affinity for plants and mineral materials.

So far, the knowledge of habitat preferences of invasive gammarids has focused mainly on Dikerogammarus villosus, which is one of the most successful aquatic invaders in Europe (van Riel et al., 2007; Hesselschwerdt et al., 2008; Bundschuh et al., 2013). On the other hand, the knowledge of the preferences of other invasive gammarids is poor. Therefore, we 
decided to evaluate experimentally the preferences of juvenile and adult $P$. robustoides for hard mineral substrata of different grain size and different types of macrophytes (natural and artificial). We assumed that larger mineral particles should be selected as offering more space for burrowing animals to move and that plants of more complex structure would be preferred over simple-shaped species. Plants can affect animal choice by their physical structure (Thomaz et al., 2008; Mormul et al., 2011) and/or chemical quality (compounds associated with their surface or released to the water column) (van Donk \& van de Bund, 2002). Therefore, we used natural plants and their artificial imitations to separate between these effects. We expected that gammarids affected by physical traits would distinguish among differently shaped plastic plants made of the same material, just as they differentiated among natural macrophytes. If chemical traits were involved in gammarid choice, we expected them to discriminate between natural and artificial plants of the same structure. Moreover, we expected differences in habitat selection between juveniles and adults, with the former being more selective, preferring relatively smaller mineral particles (due to their smaller size) and exhibiting a greater affinity for natural macrophytes (Czarnecka et al., 2010), as they feed on periphyton coating living plants while adults are more predatory (Berezina \& Panov, 2003; Berezina, 2007). We also intended to check which substratum the gammarids would select when given a choice between mineral and plant substrata. Finally, we checked the responses of juveniles to the presence of adult individuals. We hypothesized that the former would avoid substrata occupied by adults to avoid cannibalism (Platvoet et al., 2009a), choosing less preferred materials in their presence.

\section{Materials and methods}

\section{Animals}

Pontogammarus robustoides was collected by hand net from the sandy bottom (depth $0.3-0.5 \mathrm{~m}$ ) of the Włocławek Reservoir (a dam reservoir on the lower River Vistula, Central Poland, N: 52 $37^{\prime} 03^{\prime \prime}$, E: $\left.19^{\circ} 19^{\prime} 37^{\prime \prime}\right)$. After capture, the gammarids were immediately transported to the laboratory and placed in $100-1$ aquaria (water temperature: $17-19^{\circ} \mathrm{C}$ ) equipped with standard aquarium filters and aerators. The aquarium bottoms were covered by sand providing shelter for the animals. The gammarids were fed daily with frozen chironomid and chaoborid larvae. Every week, we exchanged ca. $30 \%$ of the water volume. All experiments were carried out within 1-4 weeks after the capture of gammarids. We identified the collected gammarids according to Konopacka (2004). The gammarids were divided into two age groups: juveniles (length $<7 \mathrm{~mm}$ ) and adults $(>7 \mathrm{~mm}$ ) according to Berezina (2007).

\section{Experimental set-up}

In our experiments, we used three substratum types. The first type included mineral substrata: sand (mean diameter $\pm \mathrm{SD}: 0.3 \pm 0.08 \mathrm{~mm})$, gravel $(2.0 \pm 0.60 \mathrm{~mm})$, small stones $(15 \pm 3.2 \mathrm{~mm})$, medium stones $(27 \pm$ $4.8 \mathrm{~mm})$ and large stones $(59 \pm 7.4 \mathrm{~mm})$. The second substratum type consisted of natural plants: Myriophyllum spicatum (with finely pinnately divided leaves), Ceratophyllum demersum (with small, narrow, forked leaves arranged in dense rings), Potamogeton nodosus (with large, single, lance-shaped floating leaves on long stalks), P. perfoliatus (with single, oval leaves devoid of stalks) and Stuckenia pectinata (with single, narrow, grass-like leaves). Plant species of varying structural complexity (from the most complex M. spicatum and $C$. demersum to the simplest $P$. nodosus) were chosen so as to test the preferences of gammarids with regard to plant morphology and structure. We also used the third substratum type, plastic plant imitations (used as aquarium decoration) only differing from one another in shape. We used imitations of M. spicatum, P. perfoliatus and $P$. nodosus constituting a clear structural complexity gradient as well as a gammarid selectivity gradient (from the most preferred to the least preferred plant substratum, see the "Results" section).

To quantify the structural complexity of the used natural and artificial plants, we used the fractal dimension measure (Mormul et al., 2011). Fractal dimension (D) ranges between 1 (straight line of low complexity) to 2 (fully two-dimensional figure with high complexity) and is related to the composition of macroinvertebrate assemblages (McAbendroth et al., 2005; Dibble \& Thomaz, 2009). We calculated fractal dimensions of plant perimeters on the basis of digital photographs using Image $1.40 \mathrm{~g}$ software (freeware 
Table 1 Mean $( \pm$ SD) fractal dimensions $(D)$ showing structural complexity of the plant species used in Experiments $2-5$

\begin{tabular}{lllllll}
\hline Scale & Type & P. perfoliatus & P. nodosus & S. pectinata & M. spicatum & C. demersum \\
\hline Entire plant & Natural & $1.32 \pm 0.03^{\mathrm{a}}$ & $1.23 \pm 0.01^{\mathrm{b}^{*}}$ & $1.66 \pm 0.04^{\mathrm{c}}$ & $1.67 \pm 0.01^{\mathrm{c}}$ & $1.60 \pm 0.05^{\mathrm{c}}$ \\
& Artificial & $1.30 \pm 0.03^{\mathrm{a}}$ & $1.17 \pm 0.01^{\mathrm{b}^{*}}$ & & $1.58 \pm 0.04^{\mathrm{c}}$ & \\
\multirow{2}{*}{ Leaf } & Natural & $1.10 \pm 0.01^{\mathrm{a}}$ & $1.10 \pm 0.02^{\mathrm{a}}$ & $1.20 \pm 0.04^{\mathrm{a}}$ & $1.67 \pm 0.02^{\mathrm{b}^{*}}$ & $1.44 \pm 0.04^{\mathrm{c}}$ \\
& Artificial & $1.10 \pm 0.00^{\mathrm{a}}$ & $1.12 \pm 0.01^{\mathrm{a}}$ & & $1.47 \pm 0.01^{\mathrm{b}^{*}}$ & \\
\hline
\end{tabular}

Plant species labelled with the same superscript letter did not differ significantly from one another with regard to $D$ value (Bonferroni-corrected $t$ tests following significant ANOVA effects)

Asterisks indicate significant differences in $D$ values between natural plants and their artificial analogues (Bonferroni-corrected $t$ tests)

by W. S. Rasband, U. S. National Institutes of Health, Bethesda, Maryland, USA, http://rsb.info.nih.gov/i), by means of a box count method (grid sizes: 2-512 pixels). We carried out the measurements in triplicate at two spatial scales that might be important for gammarids: entire plant scale (image pixel width: $0.2 \mathrm{~mm}$ ) and leaf scale (image pixel width: $0.03 \mathrm{~mm}$ ) (McAbendroth et al., 2005).

The structural complexity of natural plants varied significantly across species and measurement scales, as shown by a significant interaction between these factors in two-way ANOVA $\left(F_{4,20}=44.8, P<\right.$ 0.0001). M. spicatum and $C$. demersum exhibited the greatest level of complexity at both measurement scales, whereas $S$. pectinata was complex at the larger scale (when its single narrow leaves formed a net), but not at the leaf scale (Table 1). Potamogeton nodosus was the least complex species in our study. Artificial plant models used in Experiment 3 also differed significantly from one another with regard to structural complexity (a significant species $\times$ measurement scale interaction in two-way ANOVA: $F_{4,12}=29.4$, $P<0.0001)$, M. spicatum imitation being most complex and P. nodosus simplest (Table 1). Potamogeton perfoliatus was the only species for which we did not find any significant differences in complexity between artificial and natural specimens (Table 1).

Mineral substrata and artificial plants were exposed in water for at least a week before use to allow for the development of biofilm sufficient to attract gammarids (Kobak et al., 2013).

We conducted pairwise tests with two substrata presented simultaneously to 10 gammarid individuals (juveniles or adults) in two halves of a test tank (Fig. 1). The mineral substratum of a single type covered about $25 \%$ of the bottom surface at the shorter wall of the tank. The plants were presented as a bunch of shoots suspended in the water column, filling it from the bottom (with no other substratum) to the surface. This arrangement corresponded to the natural position of the studied species in the field, as they often form floating stems and leaves or occur freely in the water column. The tests were carried out in darkness. After $24 \mathrm{~h}$, we separated both substrata with a glass barrier and counted the gammarids. Most of the animals were located within the studied substrata, so we can assume that they did select a particular habitat, rather than just swimming accidentally across a given tank zone. Those few individuals (only $0.4 \%$ of all studied gammarids altogether) that were found outside the substratum (e.g. between the bare glass bottom and wall of the tank) were not included in the analysis.

\section{Experiments}

To test our working hypotheses, we conducted six experiments replicated 15 times.

Experiment 1 was carried out to test gammarid preferences for mineral substrata. To find the optimum (i.e. most selected) mineral substratum, we offered them to gammarids in pairwise combinations. These materials represented a gradient from the finest to largest particles, so we did not need to test all possible pairwise combinations of substrata. Instead, we tested neighbouring pairs of substrata along this gradient: sand vs. gravel, gravel vs. small stones, small vs. medium stones and medium vs. large stones. We stopped this series when an optimum grain size (i.e. preferred over smaller and larger particles) was found.

Experiment 2 was conducted to study gammarid preferences for natural plants. We offered plants to gammarids in all possible pairwise species combinations.

Experiment 3 was designed to check whether gammarid preferences for plants were driven by their 
Fig. 1 Experimental set-up

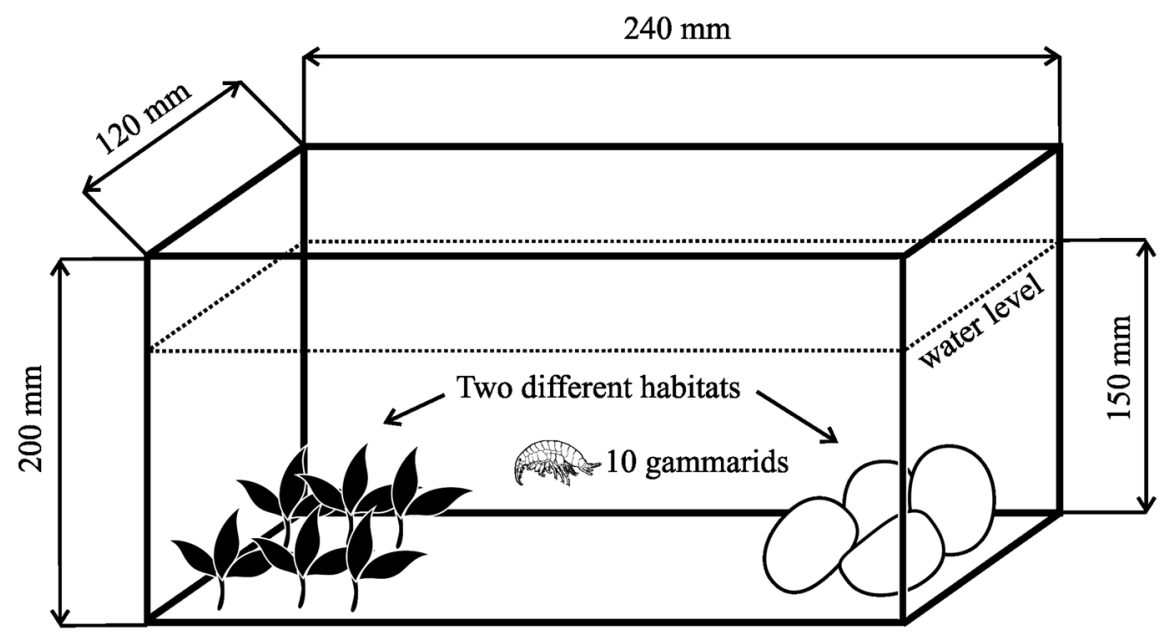

structural complexity (with no chemical cues involved). Thus, we tested gammarids in the presence of artificial plants of different shape but made of the same plastic material.

Experiment 4 was carried out to check whether gammarids used chemical cues released by plants in their habitat selection. Therefore, we offered gammarids pairs of substrata consisting of a natural plant and its plastic imitation having the same physical structure. Unfortunately, the fractal analysis showed some differences in structural complexity between natural and artificial specimens of $M$. spicatum and $P$. nodosus (Table 1). Therefore, we could only use $P$. perfoliatus in Experiment 4. Anyway, the use of all three artificial plants in Experiment 3 is justified as they still formed a clear complexity gradient.

In Experiment 5, we intended to check which of the substratum groups tested in Experiments 1-2 (macrophytes and mineral substrata) is preferred by gammarids. We tested the habitat choice made by gammarids in the presence of the most preferred materials from each group. These were $M$. spicatum (for both size classes), as well as small $(15 \mathrm{~mm})$ and medium $(27 \mathrm{~mm})$ stones (for juveniles and adults, respectively, see the "Results" section). As the result obtained for large gammarids (a clear preference for stones, see the "Results" section) was somewhat surprising, we decided to conduct an additional test using a mineral substratum less preferred by this group (i.e. small stones).

Finally, in Experiment 6, we tested the responses of juveniles to the presence of adults. We exposed each age group separately and together (10 individuals from each group) in the presence of the mineral substrata, which were most preferred (small stones, $15 \mathrm{~mm}$ in diameter) and least preferred (sand) by juveniles. Previous experiments have shown (see the "Results" section) that the stone substratum was preferred over sand by both age groups. Thus, we expected that in the mixed species treatment, adults would select stone substratum. We intended to check whether juveniles in this situation would select their preferred stony habitat despite the fact that it was occupied by adults or would switch to the less suitable sandy bottom to avoid the vicinity of large conspecifics.

\section{Data analysis}

For each pair of substrata, we tested gammarid preferences using a one-sample $t$ test comparing the mean percentage (arcsine transformed) of individuals found in one of the two offered habitats with a theoretical value of $50 \%$, expected in the case of no habitat selectivity. We also compared the distributions of adults with those of juveniles using twosample $t$ tests on the gammarid percentages (arcsine transformed) in one of the two offered habitats. To compare the selectivity of juveniles and adults kept together with those exposed separately, we applied a two-sample $\mathrm{t}$ test. To control for multiple comparisons within the same data set, we applied sequential Bonferroni corrections to the results. 


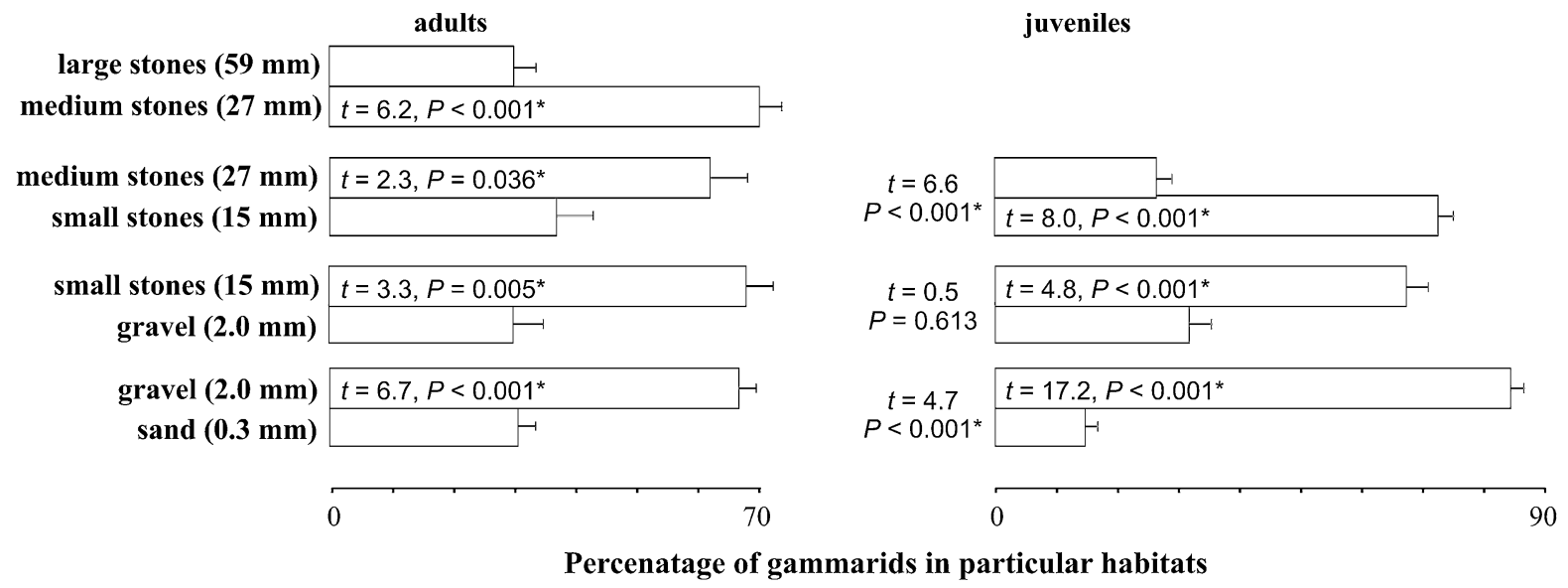

Fig. 2 Preferences of gammarids for mineral substrata (Experiment 1). Statistical results shown on the bars indicate gammarid preferences for one substratum from a given pair (one-sample $t$ tests, $\mathrm{df}=14$ ). Statistical results shown between

\section{Results}

When given a choice among various mineral substrata (Experiment 1), adult gammarids selected particles of larger diameter in combinations ranging from sand up to medium (27 mm) stones (Fig. 2). Medium stones were also preferred over large $(59 \mathrm{~mm})$ stones and thus can be regarded as the optimum choice for large gammarids. Juveniles also selected substrata with larger particles, but only in combinations ranging from sand to small $(15 \mathrm{~mm})$ stones, which were their optimum choice, preferred over coarser material (medium stones) (Fig. 2). It should be noted that both age groups preferred rocky substrata over sand, on which $P$. robustoides had naturally occurred in the field.

In Experiment 2 (selection of living macrophytes), gammarids generally chose natural plants with complex leaf structure. In particular, juveniles exhibited this type of behaviour strongly preferring M. spicatum and $C$. demersum. Both adults and juveniles selected structurally complex plants more often than a habitat formed by P. nodosus (Fig. 3). Also artificial plants of complex structure, similar to $M$. spicatum, were preferred over simpler models in Experiment 3, particularly by juveniles. Moreover, in the presence of artificial $P$. nodosus, juveniles unlike adults chose P. perfoliatus imitations (Fig. 4). In Experiment 4, adults did not differentiate between artificial and natural $P$. perfoliatus, whereas juveniles clearly the bars indicate differences in preferences between adults and juveniles ( $t$ tests for independent samples, df $=28$ ). The asterisks indicate statistically significant results

preferred natural macrophytes over their plastic analogues of the same structural complexity (Fig. 4).

When given a choice between the most preferred stone and plant substratum (Experiment 5), juvenile gammarids definitely preferred natural macrophytes. In contrast, adults selected mineral substrata, even suboptimal to them (small stones, $15 \mathrm{~mm}$ in diameter), rather than their favourite plant species (Fig. 5). In the presence of adults (Experiment 6), juveniles exhibited significantly stronger selectivity for their preferred substratum (small stones, $15 \mathrm{~mm}$ in diameter) than when kept alone, despite the fact that the same habitat was also selected by large conspecifics (Fig. 6).The behaviour of adults was unaffected by the presence of juveniles.

\section{Discussion}

In our study, $P$. robustoides clearly preferred rocky substrata, made of stones $15-30 \mathrm{~mm}$ (depending on age), over those of smaller and larger grain diameter, including sand (Experiment 1). This supports the hypothesis that a preferred substratum should have a specific structure, providing spaces corresponding to the size and morphology of the gammarid body and ensuring the highest clinging efficiency (Hacker \& Steneck, 1990). In accordance with this statement, we found a significant difference in selected substrata between juveniles and adults, with the latter selecting 


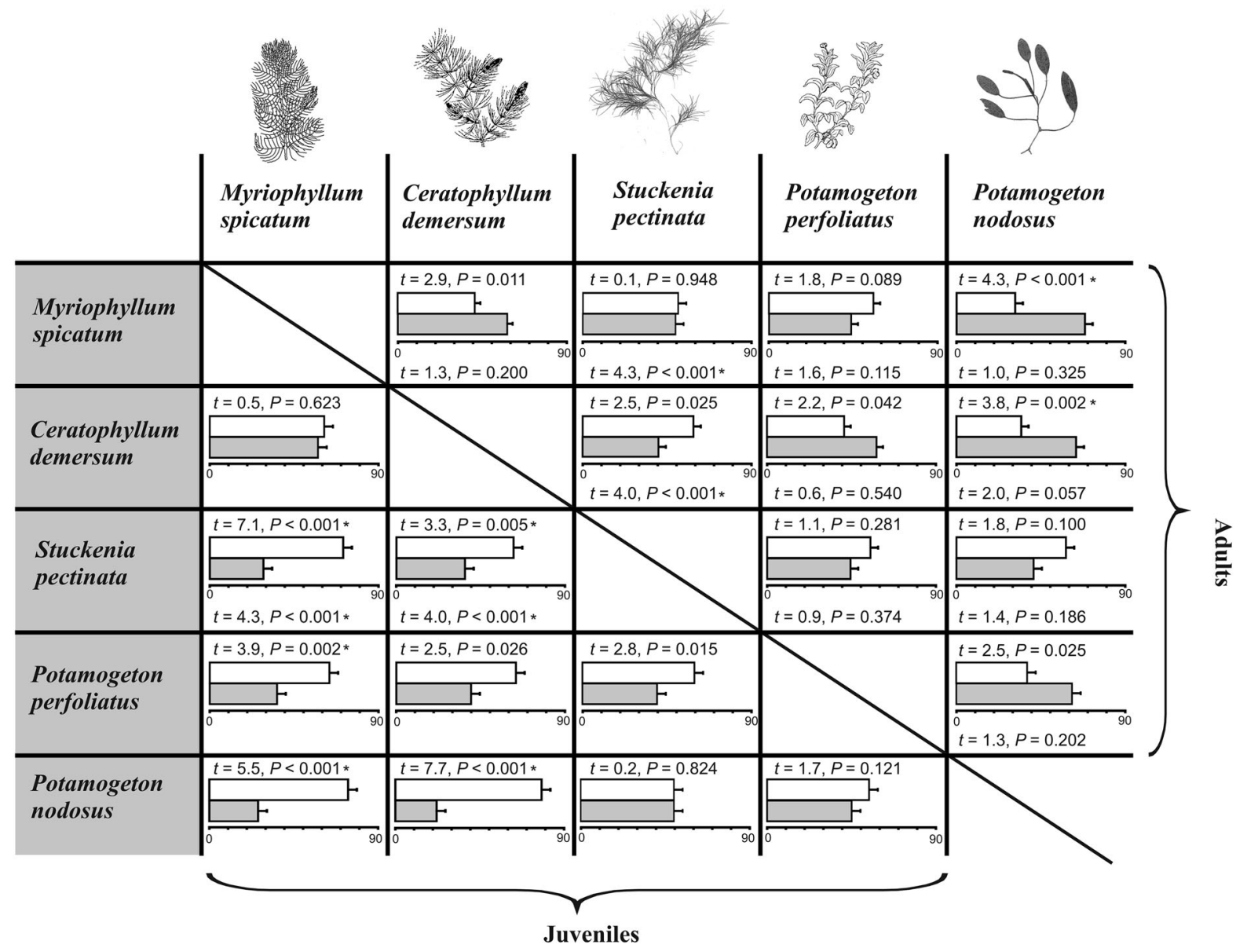

Percentages of gammarids in particular habitats

Fig. 3 Preferences of juvenile (below the diagonal) and adult (above the diagonal) gammarids for natural macrophytes (Experiment 2). Grey bars correspond to plant species given in the leftmost column, white bars refer to plant species described in the top row. Statistical results above the bars indicate gammarid preferences for one substratum from a given

bigger particles, corresponding to their larger size. These observations agree with those of the previous studies, carried out on other gammarid species: Gammarus pulex and Dikerogammarus villosus (Devin et al., 2003; Elliott, 2005; Platvoet et al., 2009a). The ability to select spaces of appropriate size can increase the survival of gammarids in the field, where they face excessive water flow and predation, including cannibalism (Platvoet et al., 2009a). Gravel and stone substrata contain abundant interstitial pores that not only serve as microhabitats but also permit a constant flow of oxygenated water and food particles (Palmer \& Ricciardi, 2004). Nevertheless, $P$. pair (one-sample $t$ tests, $\mathrm{df}=14$ ). Statistical results below the bars shown in the adult section (only significant cases are given for juveniles) indicate differences in preferences between adults and juveniles ( $t$ tests for independent samples, df $=28$ ). The asterisks indicate statistically significant results

robustoides prefers stagnant waters (Jażdżewski et al., 2002) where the bottom is covered by sand and/or plants. It has often been reported from sandy substratum (Gruszka, 1999; Żytkowicz et al., 2008) and found better adapted to it than other invasive gammarids (Poznańska et al., 2013). In spite of that, our study has shown that it clearly prefers larger particles over sand, if the former are available. This suggests a considerable plasticity of $P$. robustoides and its ability to spread in suboptimal habitats.

In our study, $P$. robustoides selected structurally complex plants, such as M. spicatum and C. demersum (Experiment 2). Preferences exhibited by juveniles 

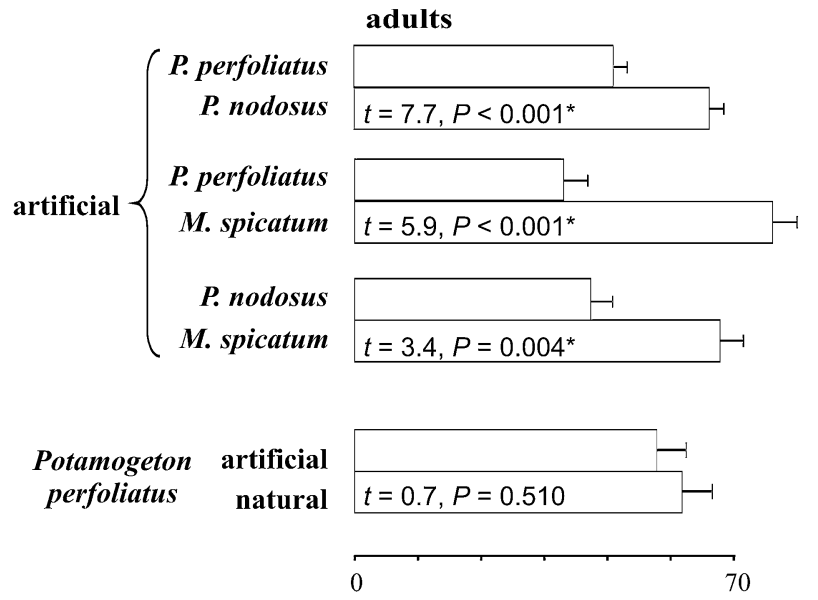
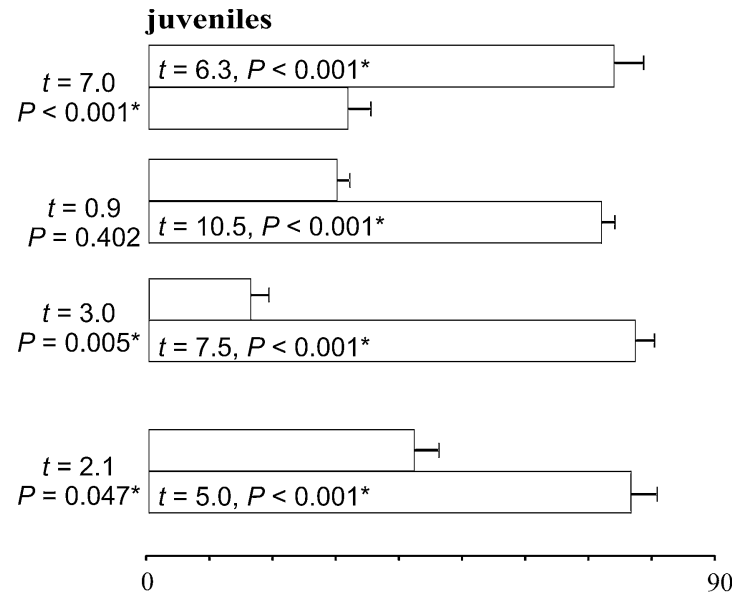

Percenatage of gammarids in particular habitats

Fig. 4 Preferences of gammarids for artificial imitations of macrophytes (Experiment 3) and their selectivity between artificial and natural plants (Experiment 4). Statistical results shown on the bars indicate gammarid preferences for one substratum from a given pair (one-sample $t$ tests, df $=14$ ).
Statistical results shown between the bars indicate differences in preferences between adults and juveniles ( $t$ tests for independent samples, $\mathrm{df}=28$ ). The asterisks indicate statistically significant results

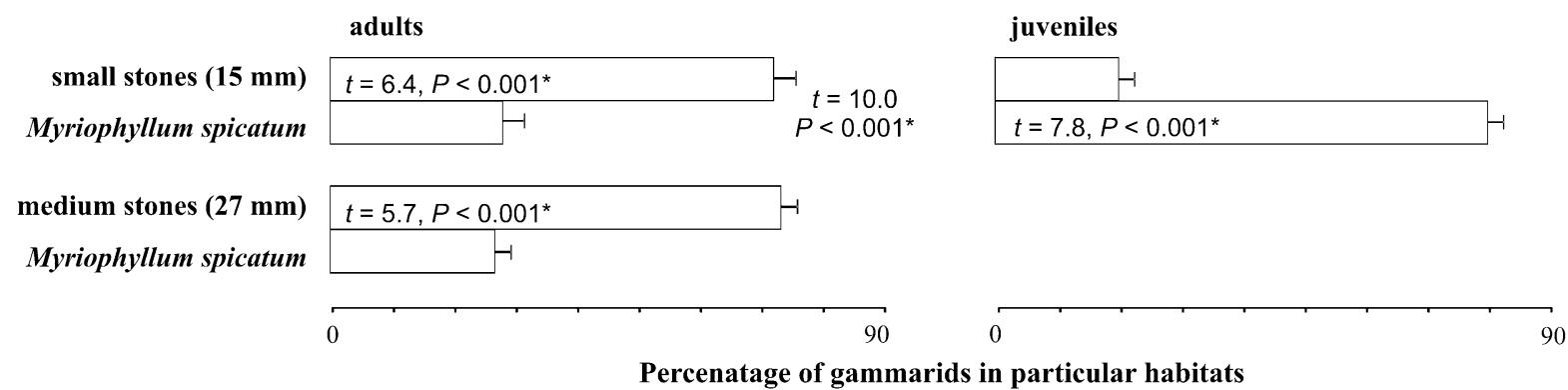

Fig. 5 Selectivity of gammarids between mineral substrata and natural macrophytes (Experiment 5). Statistical results shown on the bars indicate gammarid preferences for one substratum from a given pair (one-sample $t$ tests, $\mathrm{df}=14$ ). Statistical

were stronger, thus confirming the results of Czarnecka et al. (2010), though, in contrast to that study, we observed that the majority of adults used the most complex plant species, suggesting a kind of selectivity for complex habitats. The leaf scale seemed to be more important for gammarid choice, as S. pectinata, which was complex at the plant scale only, was not selected by them. However, we observed no significant discrimination by gammarids between the two most complex plants, M. spicatum and C. demersum, which did differ from each other with respect to leaf complexity (Table 1). This suggests that gammarids reacted to a certain threshold complexity, rather than results shown between the bars indicate differences in preferences between adults and juveniles ( $t$ tests for independent samples, $\mathrm{df}=28$ ). The asterisks indicate statistically significant results

responding gradually to a gradient. An optimum substratum structure should correspond to the size and shape of an animal body (Platvoet et al., 2009a) to offer the maximum level of protection and freedom of movement. Animals are unlikely to respond to changes in habitat complexity, which do not affect these properties. Perhaps, M. spicatum and C. demersum, though differing significantly with regard to their leaf complexity in our study, did not represent different kinds of refuges for gammarids and provided them with the same living conditions. The greater complexity index of $M$. spicatum resulted from the presence of very fine, thread-like leaflets, missing in $C$. 


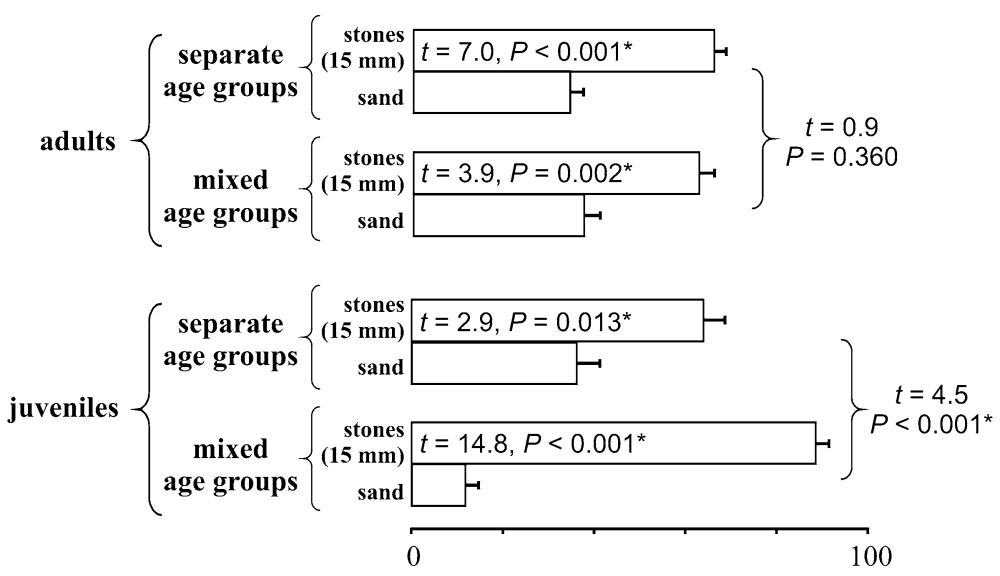

Percentage of gammarids in particular habitats

Fig. 6 Responses of gammarids to conspecifics of different size (Experiment 6). Statistical results shown on the bars indicate gammarid preferences for one substratum from a given pair (one-sample $t$ tests, $\mathrm{df}=14$ ). Statistical results shown on

demersum. These leaflets might be too narrow to be effectively used by gammarids for clinging. This would make the actual complexity of both macrophyte species for gammarids similar, as plants with many small, narrow leaves, regardless of whether they are further finely divided or not.

Gammarids of both size classes responded to plant morphology, which was confirmed by their selectivity for the plastic analogue of M. spicatum, significantly preferred over plant imitations of lower complexity (Experiment 3). Plant architecture, especially their complexity and leaf morphology or arrangement, may affect life conditions for inhabiting organisms (Van den Berg et al., 1997). In the natural environment, predation effectiveness is inversely related to the increase in plant complexity (Warfe \& Barmuta, 2004; Van de Meutter et al., 2005). Furthermore, it has been demonstrated that structurally complex habitats with a high area/volume ratio can reduce predation vulnerability and desiccation of amphipods (Gunnill, 1982; Russo, 1987). For example, residing in a complex environment provided by filamentous and branched epiphytes can be a way for Gammarus locusta to avoid predator attacks (Pavia et al., 1999).

Our experimental results show that the selectivity for plant substrata by this species is age dependent. Adults only responded to plant morphology, whereas juveniles actively preferred natural plants over their plastic analogues in Experiment 4, suggesting that the right indicate differences in preferences between single and mixed age group treatments ( $t$ tests for independent samples, $\mathrm{df}=28$ ). The asterisks indicate statistically significant results

they were affected by the quality of material forming their substratum, rather than exclusively by its complexity. Such preferences of juveniles are consistent with those found in the previous study by Czarnecka et al. (2010), who observed the affinity of small $P$. robustoides for natural plants in the presence of plastic Christmas tree branches and no such selectivity of adults. As in our present study we used $P$. perfoliatus imitations closely resembling their natural counterparts, our results unequivocally dispel potential doubts concerning the use of artificial Christmas tree branches by Czarnecka et al. (2010), differing from natural macrophytes not only in chemical composition but also in shape. In addition to these findings, we observed that both age classes also differed from each other in their responses to plant and mineral substrata (Experiment 5): adults preferred stony habitats (even including suboptimal materials, such as stones smaller than preferred) over plants, whereas juveniles clearly select plants over stones. Such habitat partitioning was also observed in other gammarid species (Devin et al., 2003; Kley et al., 2009). The differences in habitat selection by different age groups of gammarids could be accounted for by their variable foraging strategies. Adult $P$. robustoides is an omnivore with a strong tendency for predation, feeding on various benthic animals, including other amphipods (Berezina \& Panov, 2003; Arbaciauskas, 2005; Bạcela-Spychalska \& van der Velde, 2013). Individuals of a body length 
below 6-mm feed mainly on periphyton and plant detritus, though they can also consume tissues of living vascular plants (Berezina et al., 2009) or macroalgae, such as Cladophora sp. (Berezina \& Panov, 2003). Perhaps, that is why small individuals exhibit stronger affinity for natural plants. Moreover, juveniles are often endangered by relatively small invertebrate predators. Perhaps, structurally complex macrophytes provide juvenile gammarids with better protection against such enemies than larger stones, still leaving enough free space for them to live in.

In our study, we did not find any evidence of predation of adults on juveniles during $24 \mathrm{~h}$ of the experiment. However, it should be noted that gammarids usually predate on freshly moulted conspecifics (Kinzler \& Maier, 2003). Therefore, our experiments were probably too short to observe such events. Nevertheless, juveniles exposed to adults for a longer time are certainly endangered by cannibalism (Platvoet et al., 2009a), and the development of some defence mechanisms can be expected. Contrary to our expectations, juveniles did not leave their preferred substratum occupied by adults, though they did respond to the presence of larger conspecifics. Surprisingly, small gammarids increased their affinity for rocky substratum selected by co-occurring adults, despite the potential predation risk (Berezina \& Panov, 2003). Probably, endangered juveniles chose the most secure habitat, offering suitable shelters, regardless of the source and location of the danger. Juvenile $P$. robustoides has never been reported from sand in the field, usually being found on macrophytes (Czarnecka et al., 2009). The observed behaviour of juveniles could also be accounted for by their preferences for adults, which made them actively follow large conspecifics. However, as Czarnecka et al. (2010) did not observe any selectivity or avoidance of adults by juveniles when shelters were distributed all over the experimental arena, the former hypothesis seems more likely. Anyway, our results show that the avoidance of adults is not a direct mechanism differentiating habitat preferences between juveniles and adult gammarids. Nevertheless, different preferences of both size classes, as observed in our study, may be an efficient way of decreasing cannibalistic pressure of adults upon juveniles and competition between these groups for space in the field, even if the proximate factors driving their selectivity are not directly associated with the presence of conspecifics.
Our study has clearly defined the preferences of $P$. robustoides. However, field observations (unpublished data) show a somewhat different picture. The gammarids used for our experiments come from a reservoir in which this species inhabits mainly a shallow, sandy nearshore area (Żytkowicz et al., 2008). Such distribution can be explained by the limitation of more suitable habitats, indicating wide habitat tolerance. Another factor that may affect the occurrence of $P$. robustoides is a competitive species D. villosus. Areas of occurrence of these species in the Włocławek Reservoir considerably overlap (unpublished data). Furthermore, the most important mechanism for the successful invasion of $D$. villosus is direct predation on other gammarids (Dick et al., 2002; Kinzler \& Maier, 2003). Dikerogammarus villosus is able to displace other native or invasive gammarids to habitats avoided by itself (Devin et al., 2003; MacNeil \& Platvoet, 2005; Hesselschwerdt et al., 2008). Thus, the impact of this species on the habitat selectivity of $P$. robustoides would be an interesting topic for further research that could help explain the distributions of both species in the wild.

Acknowledgements Our study was supported by a grant of the National Science Centre 2012/05/B/NZ8/00479. We are grateful to Mrs. Hazel Pearson for language corrections.

Open Access This article is distributed under the terms of the Creative Commons Attribution License which permits any use, distribution, and reproduction in any medium, provided the original author(s) and the source are credited.

\section{References}

Arbaciauskas, K., 2005. The distribution and local dispersal of Ponto-Caspian Peracarida in Lithuanian fresh waters with notes on Pontogammarus robustoides population establishment, abundance and impact. Oceanological and Hydrobiological Studies 24: 93-111.

Bacela, K. \& A. Konopacka, 2005. The life history of Pontogammarus robustoides (G.O. Sars, 1894)—an alien amphipod species in Polish waters. Journal of Crustacean Biology 25: 190-195.

Bącela-Spychalska, K. \& G. van der Velde, 2013. There is more than one "killer shrimp": trophic positions and predatory abilities of invasive amphipods of Ponto-Caspian origin. Freshwater Biology 58: 730-741.

Berezina, N., 2007. Invasions of alien amphipods (Amphipoda: Gammaridea) in aquatic ecosystems of North-Western Russia: pathways and consequences. Hydrobiologia 590: 15-29. 
Berezina, N. \& V. E. Panov, 2003. Establishment of new gammarid species in the eastern Gulf of Finland (Baltic Sea) and their effects on littoral communities. Proceedings of the Estonian Academy of Sciences: Biology, Ecology 52: 284-304.

Berezina, N., S. Golubkov \& J. Gubelit, 2009. Grazing effects of alien amphipods on macroalgae in the littoral zone of the Neva Estuary (Eastern Gulf of Finland, Baltic Sea). Oceanological and Hydrobiological Studies 34: 63-82.

Bij de Vaate, A., K. Jażdżewski, H. Ketelaars, S. Gollasch \& G. Van der Velde, 2002. Geographical patterns in range extension of macroinvertebrate Ponto-Caspian species in Europe. Canadian Journal of Fisheries and Aquatic Sciences 59: 1159-1174.

Briand, F. \& J. E. Cohen, 1987. Environmental correlates of food chain length. Science 283: 956-960.

Bundschuh, M., R. Gergs, S. Schadt \& R. Schulz, 2013. Do differences in sensitivity between native and invasive amphipods explain their coexistence in Lake Constance? A case study with lambda-cyhalothrin. Chemosphere 92: 483-489.

Clark, D. S. \& J. M. Green, 1990. Activity patterns of juvenile Atlantic cod, Gadus morhua, in Conception Bay, Newfoundland, as determined by sonic telemetry. Canadian Journal of Zoology 68: 1434-1442.

Cooper, S. D., L. Barmuta, O. Sarnelle, K. Kratz \& S. Diehl, 1997. Quantifying spatial heterogeneity in streams. Journal of the North American Benthological Society 16: 174-188.

Czarnecka, M., M. Poznańska, J. Kobak \& N. Wolnomiejski, 2009. The role of solid waste materials as habitats for macroinvertebrates in a lowland dam reservoir. Hydrobiologia 635: 125-135.

Czarnecka, M., J. Kobak \& R. Wiśniewski, 2010. Preferences of juveniles and adults of the invasive Ponto-Caspian amphipod Pontogammarus robustoides for various species of macrophytes and artificial substrata. Hydrobiologia 655: 79-88.

Den Hartog, C., F. W. B. Van Den Brink \& G. Van der Velde, 1992. Why was the invasion of the river Rhine by Corophium curvispinum and Corbicula species so successful? Journal of Natural History 26: 1121-1129.

Devin, S. \& J. N. Beisel, 2008. Geographic patterns in freshwater gammarid invasions: an analysis at the pan-European scale. Aquatic Sciences 70: 100-106.

Devin, S., C. Piscart, J. N. Beisel \& J. C. Moreteau, 2003. Ecological traits of the amphipod invader Dikerogammarus villosus on a mesohabitat scale. Archiv für Hydrobiologie 158: 43-56.

Dibble, E. D. \& S. M. Thomaz, 2009. Use of fractal dimension to assess habitat complexity and its influence on dominant invertebrates inhabiting tropical and temperate macrophytes. Journal of Freshwater Ecology 24: 93-102.

Dick, J. T. A., D. Platvoet \& D. W. Kelly, 2002. Predatory impact of the freshwater invader Dikerogammarus villosus (Crustacea: Amphipoda). Canadian Journal of Fisheries and Aquatic Sciences 59: 1078-1084.

Elliott, J. M., 2005. Day-night changes in the spatial distribution and habitat preferences of freshwater shrimps, Gammarus pulex, in a stony stream. Freshwater Biology 50: 552-566.

Engström-Öst, J., E. Immonen, U. Candolin \& J. Mattila, 2006. The indirect effects of eutrophication on habitat choice and survival of fish larvae in the Baltic Sea. Marine Biology 151: 393-400.

Foster, M. S., E. W. Nigg, L. M. Kiguchi, D. D. Hardin \& J. S. Pearse, 2003. Temporal variation and succession in an algal-dominated high intertidal assemblage. Journal of Experimental Marine Biology and Ecology 289: 15-39.

Grabowski, M. \& K. Bacela, 2005. First finding of the PontoCaspian gammarid species Pontogammarus robustoides and Dikerogammarus haemobaphes (Crustacea, Amphipoda) in the post-glacial lake of the Vistula valley. Lauterbornia 55: 107-111.

Grabowski, M., K. Bacela \& A. Konopacka, 2007a. How to be an invasive gammarid (Amphipoda: Gammaroidea) comparison of life history traits. Hydrobiologia 590: 75-84.

Grabowski, M., K. Jażdżewski \& A. Konopacka, 2007b. Alien Crustacea in Polish waters - Amphipoda. Aquatic Invasions 2: $25-38$.

Gruszka, P., 1999. The River Odra estuary as a gateway for alien species immigration to the Baltic Sea basin. Acta Hydrochimica et Hydrobiologica 27: 374-382.

Gunnill, F. C., 1982. Effects of plant size and distribution on the numbers of invertebrates species and individuals inhabiting the brown alga Pelvetia fastigiata. Marine Biology 69: 263-280.

Hacker, S. D. \& R. S. Steneck, 1990. Habitat architecture and the abundance and body-size dependent habitat selection of a phytal amphipod. Ecology 71: 2269-2285.

Hesselschwerdt, J., J. Necker \& K. M. Wantzen, 2008. Gammarids in Lake Constance: habitat segregation between the invasive Dikerogammarus villosus and the indigenous Gammarus roeselii. Fundamental and Applied Limnology 173: $177-186$.

Holt, R. D., 1984. Spatial heterogeneity, indirect interactions and the coexistence of prey species. American Naturalist 124: 377-406.

Huey, R. B., 1991. Physiological consequences of habitat selection. American Naturalist 137: 91-115.

Jansson, B. O., G. Aneer \& S. Nellbring, 1985. Spatial and temporal distribution of the demersal fish fauna in a Baltic archipelago as estimated by SCUBA census. Marine Ecology Progress Series 23: 31-43.

Jażdżewski, K., A. Konopacka \& M. Grabowski, 2002. Four Ponto-Caspian and one American gammarid species (Crustacea, Amphipoda) recently invading Polish waters. Contributions to Zoology 71: 115-122.

Johnson, D. H., 1980. The comparison of usage and availability measurements for evaluating resource preference. Ecology 61: 65-71.

Kinzler, W. \& G. Maier, 2003. Asymmetry in mutual predation: possible reason for the replacement of native gammarids by invasives. Archiv für Hydrobiologie 157: 473-481.

Kley, A., W. Kinzler, Y. Schank, G. Mayer, D. Waloszek \& G. Maier, 2009. Influence of substrate preference and complexity on co-existence of two non-native gammarideans (Crustacea: Amphipoda). Aquatic Ecology 43: 1047-1059.

Kobak, J. \& J. Żytkowicz, 2007. Preferences of invasive PontoCaspian and native European gammarids for zebra mussel (Dreissena polymorpha, Bivalvia) shell habitat. Hydrobiologia 589: 43-54. 
Kobak, J., T. Kakareko, Ł. Jermacz \& M. Poznańska, 2013. The impact of zebra mussel (Dreissena polymorpha) periostracum and biofilm cues on habitat selection by a PontoCaspian amphipod Dikerogammarus haemobaphes. Hydrobiologia 702: 215-226.

Konopacka, A., 2004. Inwazyjne skorupiaki obunogie (Crustacea, Amphipoda) w wodach Polski. [Invasive amphipods (Crustacea, Amphipoda) in Polish waters]. Przegląd Zoologiczny 4: 141-162.

Kovalenko, K. E., S. M. Thomaz \& D. M. Warfe, 2012. Habitat complexity: approaches and future directions. Hydrobiologia 685: 1-17.

Lehtinen, R. M. \& G. L. F. Carfagno, 2011. Habitat selection, the included niche, and coexistence in plant-specialist frogs from Madagascar. Biotropica 43: 58-67.

MacNeil, C. \& D. Platvoet, 2005. The predatory impact of the freshwater invader Dikerogammarus villosus on native Gammarus pulex (Crustacea: Amphipoda); influences of differential microdistribution and food resources. Journal of Zoology 267: 31-38.

MacNeil, C. \& D. Platvoet, 2013. Could artificial structures such as fish passes facilitate the establishment and spread of the "killer shrimp" Dikerogammarus villosus (Crustacea: Amphipoda) in river systems? Aquatic Conservation Marine and Freshwater Ecosystems 23: 667-677.

McAbendroth, L., P. M. Ramsay, A. Foggo, S. D. Rundle \& D. T. Bilton, 2005. Does macrophyte fractal complexity drive invertebrate diversity, biomass and body size distributions. Oikos 111: 279-290.

Mormul, R. P., S. M. Thomaz, A. M. Takeda \& R. D. Behrend, 2011. Structural complexity and distance from source habitat determine invertebrate abundance and diversity. Biotropica 43: 738-745.

Murdoch, W. W. \& A. Oaten, 1975. Predation and population stability. Advances in Ecological Research 9: 1-131.

Murphy, P. J., 2003. Does reproductive site choice in a neotropical frog mirror variable risks facing offspring? Ecological Monographs 73: 45-67.

Palmer, M. E. \& A. Ricciardi, 2004. Physical factors affecting the relative abundance of native and invasive amphipods in the St. Lawrence River. Canadian Journal of Zoology 82: 1886-1893.

Pavia, H., H. Carr \& P. Aberg, 1999. Habitat and feeding preferences of crustacean mesoherbivores inhabiting the brown seaweed Ascophyllum nodosum (L.) Le Jol. and its epiphytic macroalgae. Journal of Experimental Marine Biology and Ecology 236: 15-32.

Platvoet, D., J. T. A. Dick, C. MacNeil, M. C. Riel \& G. Van der Velde, 2009a. Invader-invader interactions in relation to environmental heterogeneity leads to zonation of two invasive amphipods, Dikerogammarus villosus (Sowinsky) and Gammarus tigrinus Sexton: Amphipod Pilot Species Project (AMPIS) report 6. Biological Invasions 11: 2085-2093.

Platvoet, D., G. Van der Velde, J. T. A. Dick \& S. Q. Li, 2009b. Flexible omnivory in Dikerogammarus villosus (Sowinsky, 1894) (Amphipoda) - Amphipod Pilot Species Project (AMPIS) Report 5. Crustaceana 82: 703-720.

Poznańska, M., T. Kakareko, M. Krzyżyński \& J. Kobak, 2013. Effect of substratum drying on the survival and migrations of Ponto-Caspian and native gammarids (Crustacea: Amphipoda). Hydrobiologia 700: 47-59.

Pulliam, H. R. \& B. J. Danielson, 1991. Sources, sinks, and habitat selection: a landscape perspective on population dynamics. American Naturalist 137: 50-66.

Raizer, J. \& M. E. C. Amaral, 2001. Does the structural complexity of aquatic macrophytes explain the diversity of associated spider assemblages? Journal of Arachnology 29: 227-237.

Russo, A. R., 1987. Role of habitat complexity in mediating predation by the gray damselfish Abudefduf sordidus on epiphytal amphipods. Marine Ecology Progress Series 36: 101-105.

Scealy, J. A., S. J. Mika \& J. Boulton, 2007. Aquatic macroinvertebrate communities on wood in an Australian lowland river: experimental assessment of the interactions of habitat, substrate complexity and retained organic matter. Marine and Freshwater Research 58: 153-165.

Schiel, D. R., 2004. The structure and replenishment of rocky shore intertidal communities and biogeographic comparisons. Journal of Experimental Marine Biology and Ecology 300: 309-342.

Sih, A., 1980. Optimal behavior: can foragers balance two conflicting demands? Science 210: 1041-1043.

Taniguchi, H. \& M. Tokeshi, 2004. Effects of habitat complexity on benthic assemblages in a variable environment. Freshwater Biology 49: 1164-1178.

Taniguchi, H., S. Nakano \& M. Tokeshi, 2003. Influences of habitat complexity on the diversity and abundance of epiphytic invertebrates on plants. Freshwater Biology 48: 718-728.

Thomaz, S. M., E. D. Dibble, L. R. Evangelista, J. Higuti \& L. M. Bini, 2008. Influence of aquatic macrophyte habitat complexity on invertebrate abundance and richness in tropical lagoons. Freshwater Biology 53: 358-367.

Van de Meutter, F., R. Stoks \& L. De Meester, 2005. Spatial avoidance of littoral and pelagic invertebrate predators by Daphnia. Oecologia 142: 489-499.

Van den Berg, M. S., H. Coops, R. Noordhuis, J. Van Schie \& J. Simons, 1997. Macroinvertebrate communities in relation to submerged vegetation in two Chara-dominated lakes. Hydrobiologia 342: 143-150.

Van der Velde, G., S. Rajagopal, B. Kelleher, I. B. Musko \& A. Bij de Vaate, 2000. Ecological impact of crustacean invaders: general considerations and examples from the Rhine River. Crustacean Issues 12: 3-33.

Van Donk, E. \& W. J. van de Bund, 2002. Impact of submerged macrophytes including charophytes on phyto-and zooplankton communities: allelopathy versus other mechanisms. Aquatic Botany 72: 261-274.

Van Riel, M. C., G. Van der Velde, S. Rajagopal, S. Marguillier, F. Dehairs \& A. Bij de Vaate, 2006. Trophic relationships in the Rhine food web during invasion and after establishment of the Ponto-Caspian invader Dikerogammarus villosus. Hydrobiologia 565: 39-58.

Van Riel, M. C., E. P. Healy, G. Van der Velde \& A. Bij de Vaate, 2007. Interference competition among native and invader amphipods. Acta Oecologica 31: 282-289. 
Warfe, D. M. \& L. A. Barmuta, 2004. Habitat structural complexity mediates the foraging success of multiple predator species. Oecologia 141: 171-178.

Whitehead, H. \& S. J. Walde, 1992. Habitat dimensionality and mean search distances of top predators: implications for ecosystem structure. Theoretical Population Biology 42: 1-9.
Żytkowicz, J., J. Kobak, T. Kakareko \& A. Kentzer, 2008. Species composition and distribution of invasive PontoCaspian amphipods in the off-channel microhabitats of a temperate, lowland dam reservoir. International Review of Hydrobiology 93: 62-72. 